\title{
ГОСУДАРСТВЕННАЯ ПРОГРАММА РФ «УПРАВЛЕНИЕ ФЕДЕРАЛЬНЫМ ИМУЩЕСТВОМ»: ЭТО ПРОГРАММА ПОВЫШЕНИЯ ЭФФЕКТИВНОСТИ УПРАВЛЕНИЯ ФЕДЕРАЛЬНЫМ ИМУЩЕСТВОМ ИЛИ ПРОГРАММА ПРИВАТИЗАЦИИ?
}

\author{
(c) 2018 Звягинцев Петр Семенович \\ кандидат экономических наук, старший научный сотрудник \\ Институт экономики Российской академии наук \\ 117218, г. Москва, Нахимовский проспект, 32 \\ E-mail:petrz@bk.ru
}

В статье рассматривается государственная программа Российской Федерации «Управление федеральным имуществом», ее содержание и трансформация. Приведены темпы сокращения имущества государственной казны и количества организаций с государственным участием в 2013-2020 гг., а также удельный вес имущества государственной казны Российской Федерации и количества организаций с государственным участием в 2020 году в процентах по сравнению с 2012 г. Обосновывается вывод о необходимости сохранения эффективных государственных предприятий, создание условий для эффективного управления федеральным имуществом.

Ключевые слова: государственная программа, федеральное имущество, управление, приватизация, эффективность.

Распоряжением Правительства Российской Федерации от 16.02.2013 г. № 191-р была утверждена государственная программа РФ «Управление федеральным имуществом» [1], а 15 апреля 2014 г. Правительство РФ своим постановлением за № 327 утвердило государственную программу РФ «Управление федеральным имуществом», которая была существенно изменена [2].

\section{Основные цели Программы:}

1. Создание условий для эффективного управления федеральным имуществом, необходимым для выполнения государственных функций органами государственной власти Российской Федерации и отчуждения федерального имущества, востребованного в коммерческом обороте.

2. Совершенствование системы государственного материального резерва, повышение ее роли в позитивных процессах, происходящих в экономике и политике Российской Федерации и направленных на укрепление экономической независимости и национальной безопасности государства.

Ожидаемые результаты реализации Программы:

- оптимизация состава и структуры федерального имущества на макроуровне и микроуровне в интересах обеспечения устойчивых предпосылок для экономического роста:
- повышение эффективности управления федеральным имуществом, включая развитие конкурентоспособности и инвестиционной привлекательности компаний с государственным участием с определением долго- и краткосрочных целей и задач управления, повышения уровня их корпоративного управления и информационной прозрачности;

- ограничение расширения государственного сектора экономики;

- обеспечение обновления основных фондов государственного материального резерва.

Срок реализации Программы был определен с 2013 г. до 2018 г.

Постановлением Правительства РФ от 31 марта 2017 г. № 381-12 были внесены изменения в государственную программу Российской Федерации «Управление федеральным имуществом» [3].

Несмотря на то, что Программа выполнялась уже более 4 лет, в нее были внесенные существенные изменения: цели и задачи и целевые индикаторы и показатели; сроки реализации Программы; объемы бюджетных ассигнований; ожидаемые результаты.

В измененной Программе (2017 г.) цель: совершенствование механизмов управления и приватизации федерального имущества, была заменена на ранее поставленную цель: «Со- 
здание условий для эффективного управления федеральным имуществом, необходимым для выполнения государственных функций органами государственной власти Российской Федерации, и отчуждения федерального имущества, востребованного в коммерческом обороте». В тексте измененной Программы нет упоминания о совершенствовании каких-либо механизмов управления федерального имущества.

Также изменились и ожидаемые результаты реализации Программы: завершение к 2019 г. реформирования системы продажи федерального имущества; увеличение динамики сокращения имущества государственной казны Российской Федерации с 3 процентов в 2013 году до 24 процентов в 2019 г.

30 марта 2018 г. № 367-14 Правительства РФ утверждает (третье) Постановление «О внесении изменений в государственную программу Российской Федерации «Управление федеральным имуществом» [4].

В Программе увеличиваются сроки ее реализации с 2019 года до 2020 года, а также изменены ожидаемые результаты реализации Программы и объемы бюджетных ассигнований. Теперь ожидаемые результаты реализации Программы записаны так: утвержден к 2020 году прогнозный план приватизации федерального имущества и основные направления приватизации федерального имущества на 2020-2022 годы.

Сокращения имущества государственной казны Российской Федерации увеличиваются с $24 \%$ в 2019 году до 29,5\% в 2020 году, а сокращения количества организаций с государственным участием также увеличиваются соответственно с $10 \%$ до $10,5 \%$ (см. рис. 1).

За 8 лет (2013-2020 гг.) реализации программы сокращения (приватизация) имущества государственной казны Российской Федерации оно уменьшится в 2020 году до $21,9 \%$ по отношению к 2012 году, т.е. сократится в 4,57 раза, а количество организаций с государственным участием составит соответственно 42,23\%, сократившись в 2,37 раза по отношению к 2012 году (см. рис. 2).

Согласно результатам реализации измененной Программы, приватизация федерального имущества будет продолжена до 2022 года.

Следовательно, ожидаемые результаты реализации Программы (2014 г.) не будут реализованы: оптимизация состава и структуры федерального имущества на макроуровне и микроуровне в интересах обеспечения устойчивых предпосылок для экономического роста, а также повышение эффективности управления федеральным имуществом, включая развитие конкурентоспособности и инвестиционной привлекательности компаний с государственным участием с определением долго- и краткосрочных целей и задач управления, повышения уровня их корпоративного управления и информационной прозрачности.

Как можно проводить оптимизацию соста-

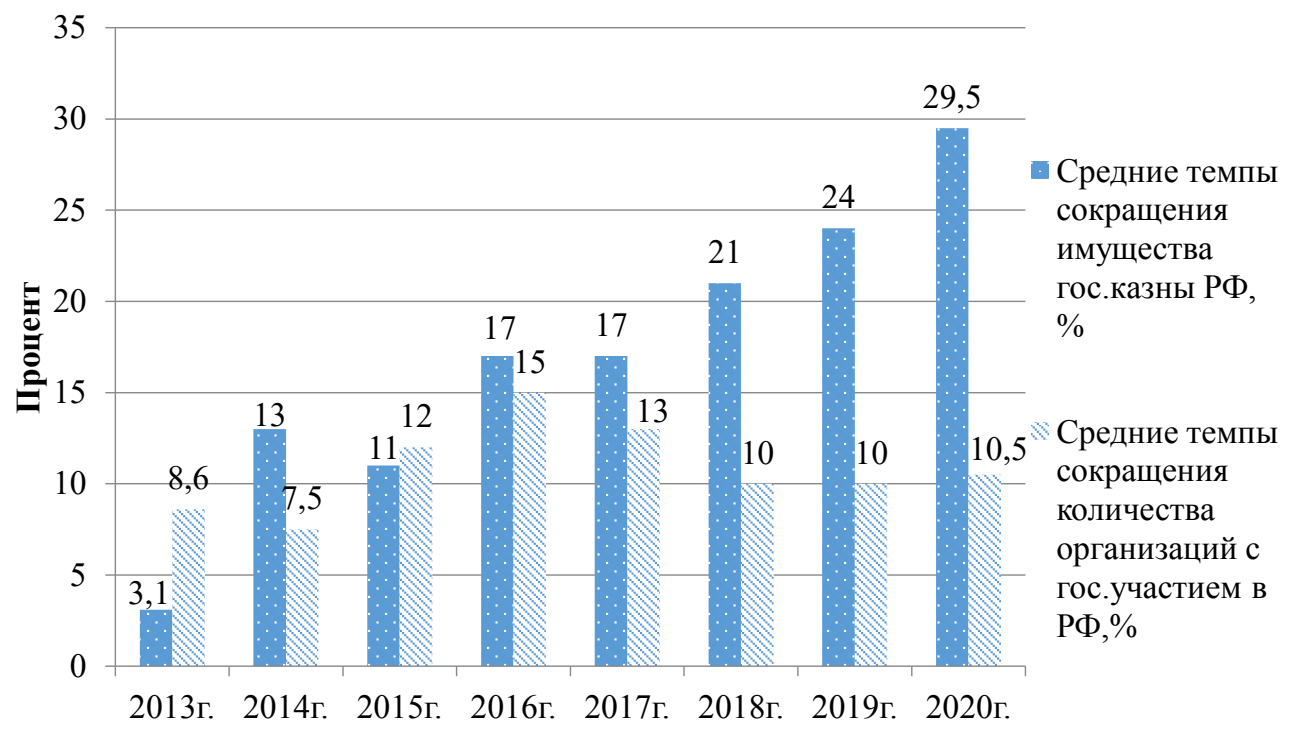

Puc. 1. Темпы сокращения имущества государственной казны и количества организаций с государственным участием в 2013-2020 гг.

Источник: постановление Правительства РФ от 30 марта 2018 г. № 367-14 «О внесении изменений в государственную программу Российской Федерации «Управление федеральным имуществом». 


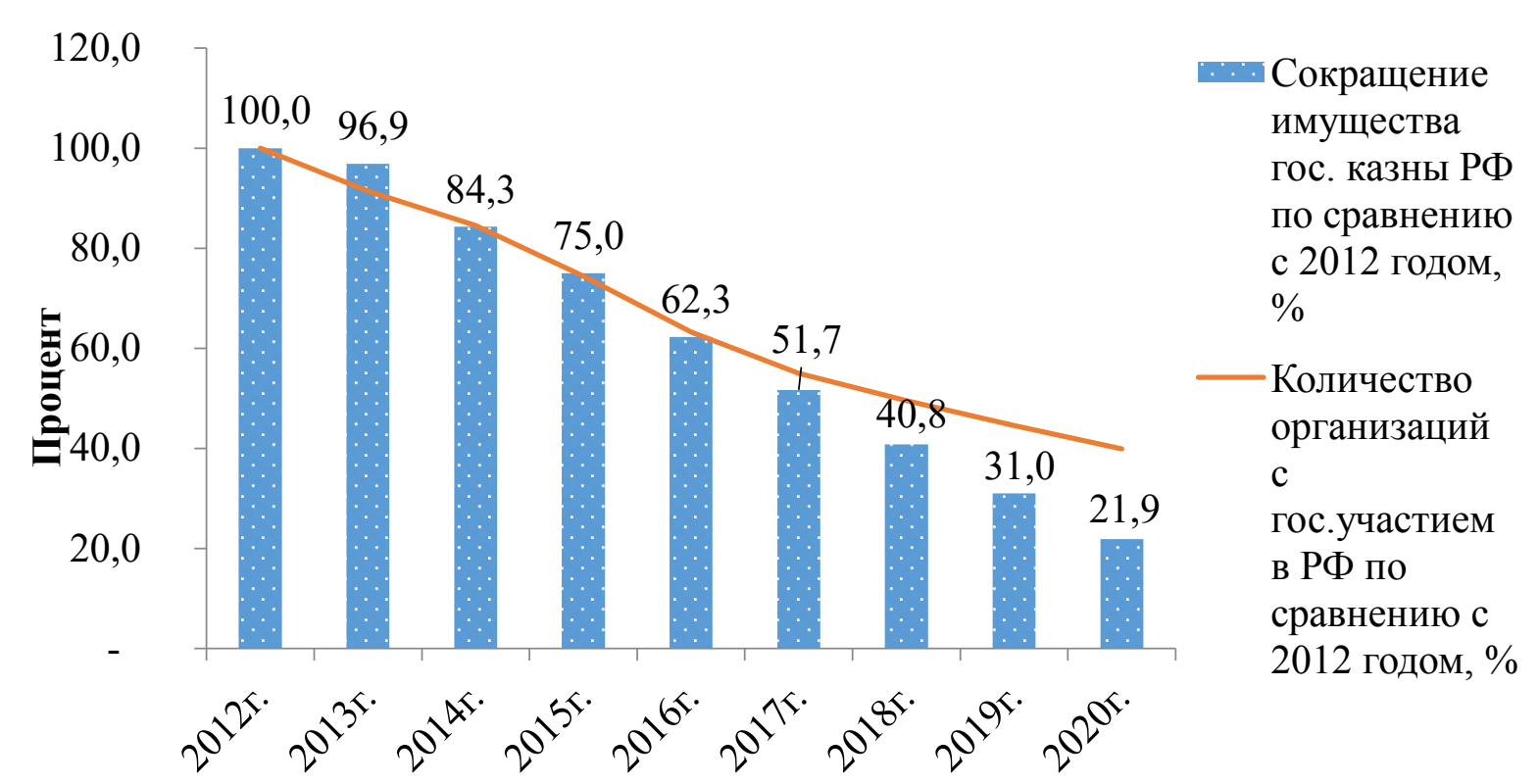

Puc. 2. Сокращения имущества государственной казны Российской Федерации и количества организаций с государственным участием в 2013-2020 годы по сравнению с 2012 г.,\% Источник. Расчет автора на основе данных Программы.

ва и структуры федерального имущества на макро- и микроуровне в интересах обеспечения устойчивых предпосылок для экономического роста, если задания на сокращения количество организаций и имущества меняли несколько раз в сторону увеличения?

По данным Росстата, на начало 2018 г. в госсобственности находится 2,25\% предприятий, в собственности общественных и религиозных организаций $-3,1 \%$, в смешанной собственности $-4,1 \%$, в муниципаль-ной $-4,3 \%$, а в частной собственности $-86,28 \%$ (см. рис. 3). За десять лет (2007-2017 гг.) количество предприятий с государственной собственностью сократились на $30,84 \%$, а с частной - увеличилось на $8,17 \%$ [5].

В государственных корпорациях доля частного капитала велика. Так, в большинстве сырьевых компаний до $50 \%$ акций и активов принадлежит частным структурам, в том числе зарубежным компаниям.

В добыче и реализации нефти в России более $75 \%$ объёмов занимают частные структуры. В АвтоВАЗе группа «Рено-Ниссан» имеет 75\%, а в «Ростехе» $-25 \%$, в концерне «Калашников» частная собственность составляет 49\% [6].

По мнению директора Института анализа предприятий и рынков Андрея Яковлева «дело не в частной или государственной собственности». Есть и вполне эффективные госкорпорации, например в Норвегии, Чили, Малайзии. Вопрос в качестве государства - может ли оно эффективно распоряжаться своей собственностью и регулировать частные рынки, может ли отделить добросовестных чиновников от коррумпированных, объясняет он. Без решения проблемы конфликта интересов приватизация и сокращение присутствия государства не помогут [6].

В работах сотрудников Института экономики РАН также отмечается, что «вызывает большие сомнения, что дальнейшая приватизация предприятий с государственным участием в условиях неразвитого гражданского общества в России обеспечит рост российской экономики» [7]; «в условиях возникающих бюджетных ограничений и экономических санкций значительная роль в реализации новой стратегии экономического развития в нашей стране будет сохраняться за государственными ресурсами и государственными предприятиями (в т.ч. сектор ОПК), которые оказывают существенное влияние на эффективность функционирования российской экономики» [8].

Следовательно, передача государственных предприятий в частные руки не гарантирует их эффективность, и особенно в России.

Кроме того, зачем приватизировать прибыльные государственные предприятия, которые могут после приватизации перейти в оффшоры и не платить налоги или совсем закрыться?

Ответ на этот вопрос дает Минэкономразвития РФ: приватизация является одним из источников бюджетных доходов [9].

По мнению министра финансов Силуанова 


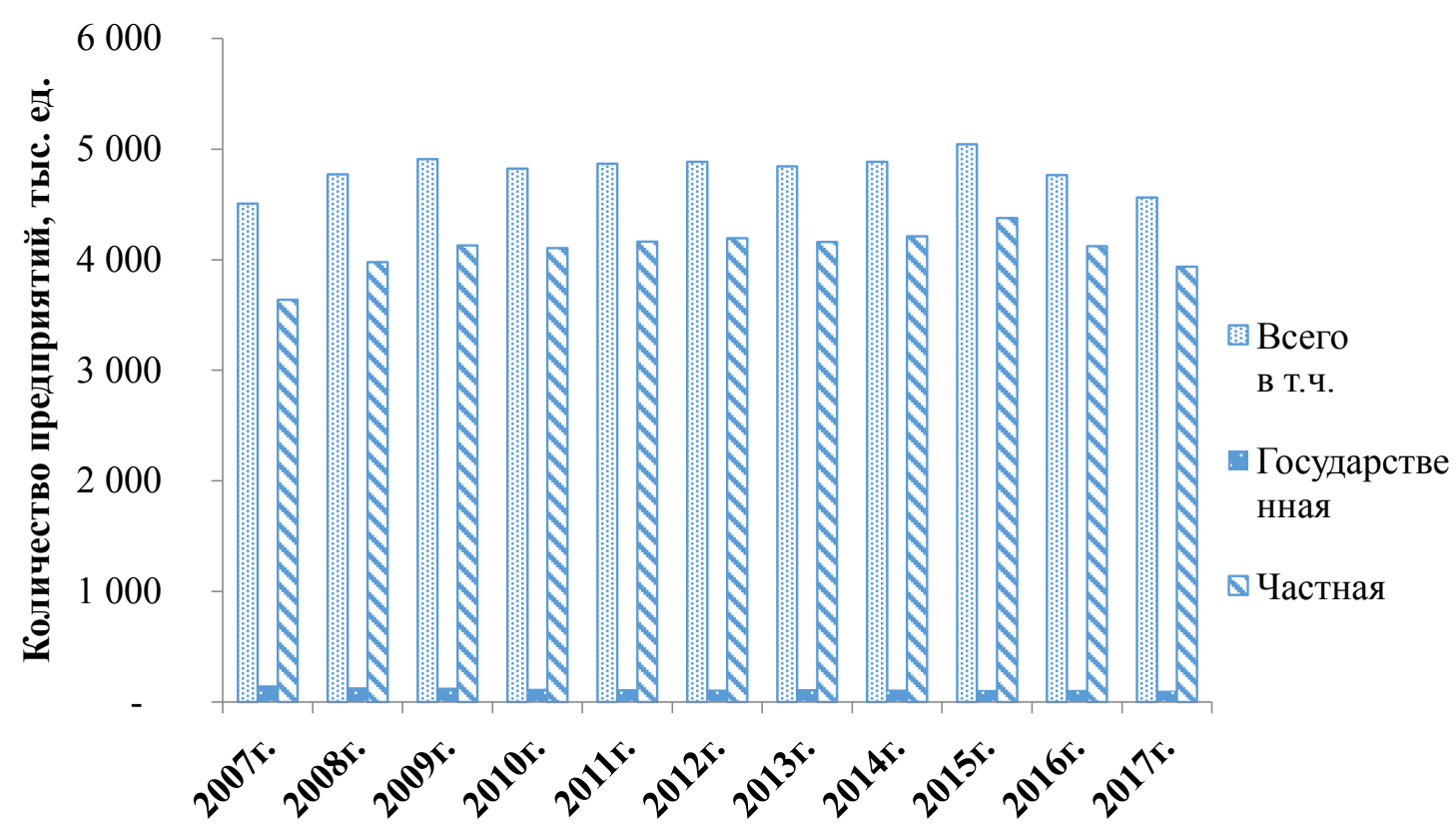

Puc. 3. Распределение предприятий и организаций по формам собственности в 2006-2017 гг. Источник: Россия в цифрах. 2007, 2014, 2018: Крат. стат. сб. М.: Росстат, 2007, 2014, 2018. С. 176, 205, 208.

«за развитие страны государство не должно отвечать, если правительство не будет вкладывать свободные деньги в США, то россияне их «проедят» [10]. Следовательно, частные лица должны строить заводы и проводить индустриализацию.

В Указе президента России Владимира Путина N444 от 19.07.2018 г. «О национальных целях и стратегических задачах развития Российской Федерации на период до 2024 года» правительство Российской Федерации должно обеспечить достижение вхождение Российской Федерации в число пяти крупнейших экономик мира, обеспечить темпы экономического роста выше мировых при сохранении макроэкономической стабильности [11].

Глава правительства России Дмитрий Медведев, сообщил депутатам, что на исполнение планов президента потребуется 25 триллионов рублей, из которых надо найти не менее 8 триллионов рублей [12].

Однако ни президент, ни глава правительства об этом не сказали: откуда взять денежные средства на выполнение Указа. Сейчас правительство нашло финансовые источники для выполнения Указа Президента: реализация пенсионной реформы, повышения НДС и другие.

Кроме этого, глава правительства России Дмитрий Медведев в своем высказывании о финансовом источнике наполнения бюджета - «это новая волна приватизации Госсоб- ственности» [13]. Это означает, что власть хочет еще больше и больше, чтобы заработать на этом приличное количество денег. Для этого придется все больше передавать Госкорпорации и другие предприятия в частные руки.

В тоже время экономист Делягин уверен, что Россия не будет развиваться, пока не пересмотрят итоги приватизации 90-х. Если экономика будет национализирована, считает Делягин, то Россия может конкурировать с западом на равных. Пока же Россия - сырьевой придаток [14].

По высказыванию Кудрина, каким образом Россия может стать пятой экономикой мира, находясь сейчас на 11 месте? Очевидно, это будет возможно только в том случае, если изменится экономическая и общественная система, то есть, если изменятся даже социальные основы самого государства [15].

Таким образом, результатом реализации государственной Программы «Управление федеральным имуществом» является распродажа государственной собственности, которая будет и дальше продолжаться, тем самым, игнорируя мировой опыт эффективного использования государственных и народных предприятий, которые имеются в России. Без государственных эффективных предприятий не удается осуществлять масштабные научно-технические программы и сглаживать региональные проблемы развития. 


\section{Библиографический список}

1. Распоряжение Правительства Российской Федерации от 16.02.2013 г. № 191-р была утверждена государственной программы РФ «Управление федеральным имуществом».

2. Постановление Правительства РФ от 15 апреля 2014 г. № 327 «Об утверждении государственной программы Российской Федерации «Управление федеральным имуществом».

3. Постановление Правительства РФ от 31 марта 2017 г. № 381-12 «О внесении изменений в государственную программу Российской Федерации «Управление федеральным имуществом».

4. Постановление Правительства РФ от 30 марта 2018 г. № 367-14 «О внесении изменений в государственную программу Российской Федерации «Управление федеральным имуществом».

5. Россия в цифрах. 2018: Крат. стат. сб. М.: Росстат, 2018. С. 208.

6. Мереминская E. ФАС признала государство главным врагом конкуренции // Ведомости. https://www. vedomosti.ru/economics/ articles/ 2016/09/29/658959-goskompanii-kontroliruyut-ekonomiki (дата обращения 25 октября 2018 г.).

7. Грибанова О.М. Концепция управления государственным имуществом: оценка и перспективы развития. // Вестник института экономики Российской академии наук. 2017. № 4. С. 90-97.

8. Смотрицкая И. И. Новая экономическая стратегия требует нового качества государственного управления.// Вестник института экономики Российской академии наук. 2017. № 5. С. 7-22.

9. Звягинцев П.С. Государственная программа Российской Федерации «Управления федеральным имуществом» как инструмент регулирования государственного сектора. // Вестник института экономики Российской академии наук. 2017. № 6. С. 61-73.

10. https://zen.yandex.ru/media/etc/siluanov-esli-pravitelstvo-ne-budet-vkladyvat-svobodnye-dengi-v-ssha-torossiiane-ih-proediat-5ba469dec071d300ab51bc88

11. Указ Президента РФ 19.07.2018 г. N444 «О национальных целях и стратегических задачах развития Российской Федерации на период до 2024 года».

12. https://news.mail.ru/politics/33405737/

13. https://zen.yandex.ru/media/government/medvedev-zaiavil-o-gotovnosti-k-novoi-volne-privatizacii-gossobstve nnosti-5ba515ee8f43c900aac8326f

14. https://zen.yandex.ru/media/etc/deliagin-pora-v-rossii-provodit-nacionalizaciiu-5b51d92645108800aa31dfb6? \&from=feed

15. http://zavtra.ru/blogs/kudrin_predlagaet_sdat_sya 